\title{
Intraoperative visual experience and preoperative counselling during phacoemulsification under topical anaesthesia
}

\author{
Shakya K' , Pokhrel SP2 , Pokhrel RP³, Malla OK ${ }^{4}$
}

${ }^{1}$ Kiran Shakya, Lecturer; ${ }^{2}$ Suprada Pokhrel Pandey, Assistant Professor; ${ }^{3}$ Ram Prasad Pokhrel, Professor; ${ }^{4}$ Om Krishna Malla, Professor; Department of Ophthalmology, Kathmandu Medical College Teaching Hospital, Kathmandu, Nepal

\begin{abstract}
Background: Phacoemulsification surgery using topical anaesthesia makes patient experience a multitude of visual sensations. However, it makes cataract surgery safe with the quickest visual recovery.

Objective: To find the effect of preoperative counselling about potential intraoperative visual experience during phacoemulsification under topical anaesthesia to alleviate fear in patients having cataract surgery.

Methods: This non- randomized and non comparative study was carried out in a tertiary care hospital from February 2015 to April 2015. Forty five adult patients underwent cataract surgery (phacoemulsification with foldable intraocular lens implantation) under topical anaesthesia using Proparacaine hydrochloride $0.5 \%$ eye drops by a single surgeon. All patients received counselling on the potential intraoperative visual experience during phacoemulsification. A structured questionnaire was used to collect data on socio-demographics, pain, intraoperative visual experiences and their fear. Participants were asked if they experienced visual sensations such as light perception, gush of water and movements during surgery.

Results: Nineteen $(42.2 \%)$ of them were men and $26(57.8 \%)$ were women. Sixty nine percent of the patients were above 60 years. All of them reported having experienced visual sensations during surgery, the most common being light perception (100\%), movements of instruments or surgeon's hands $(91.1 \%)$ and gush of water $(62.2 \%)$. One case (4.4\%) felt tolerable pain associated with fear $(\mathrm{P}=0.000)$ due to these visual experience.

Conclusion: Preoperative counselling about the potential intraoperative visual experience during phacoemulsification under topical anaesthesia alleviates the visual experience fear in patients having cataract surgery.
\end{abstract}

Key words: Phacoemulsification, Preoperative counselling, Topical anaesthesia, Visual experience

\section{INTRODUCTION}

$\mathrm{P}$ hacoemulsification surgery using topical anaesthesia has made cataract surgery more successful as the anaesthesia has several advantages over regional infiltrative techniques, such as peribulbar, retrobulbar and subtenon injection, the foremost of which is the quickest visual recovery and the abolition of any risk of inadvertent injury to the globe or orbital contents' ${ }^{1}$.

The drops which are applied a few minutes before surgery are sufficient for anaesthesia and to perform phacoemulsification through a corneal incision. The fear that the patients under topical anesthesia experience is

Address for correspondence

Dr. Kiran Shakya

Lecturer, Department of Ophthalmology

Kathmandu Medical College Teaching Hospital

Sinamangal, Kathmandu, Nepal

E-mail: kiranshakya2001@gmail.com attributed to the visual sensation they receive. Studies have reported that a significant proportion of patients undergoing cataract surgery may experience a multitude of visual sensations intraoperatively ${ }^{2-9}$.

This study focused on different types of visual sensation perceived by patients during surgery under topical anaesthesia after proper counselling about instruments and procedure.

\section{METHODS}

This non- randomized and non comparative study was carried out in a tertiary care hospital, from February 2015 to April 2015. Forty five adults patients age 40-80 years, underwent cataract surgery (phacoemulsification with foldable intraocular lens implantation) under topical anaesthesia were included.They were recruited using convenient sampling method. All patients received counselling on the potential intraoperative 
visual experience before phacoemulsification surgery. Informed consent was obtained from every subject before their enrollment in the study. Those who had mature cataract, subluxated lens and complicated cataract, and did not want to enroll in the study were excluded. Ethical clearance was obtained from the Institutional Review Committee. Each participant was interviewed 10-15 minutes after completion of the cataract surgery. A structured questionnaire was used to collect data on socio-demographics, intraoperative visual experiences and their fear. Participants were asked if they experienced visual sensations such as light perception, gush of water and movements during surgery. Moreover, subjects were asked if they experienced any fear due to the different visual stimuli experienced during the procedure.

Initial screening examinations consisted of Uncorrected Visual Acuity (UCVA), pinhole visual acuity, pupil and slit-lamp examination with Haag Streit 900, Fundus Examination Under Mydriasis (FEUM) with 90D and 20D, intraocular pressure measurement, blood glucose measurement and blood pressure measurement. Biometry was performed before the operation on all patients with the use of a keratometer and a $A$ scan (Tomey) for the axial length calculations and determination of the Intra Ocular Lens (IOL) power. All patients were advised to instill Ofloxacin eye drop four times one day prior to surgery. A single drop of topical anaesthesia using Proparacaine hydrochloride $0.5 \%$ eye drop was installed three times for every two minutes before surgery. The patients were brought to the operating room where the eye was painted with betadine and draped for cataract surgery.

\section{SURGICAL METHOD}

All surgeries were performed by a single surgeon. After ascertaining painlessness to patient by pinching conjunctiva of operating eye with plain forceps, the patient was instructed to fix the eye at light of operating microscope. The clear corneal tunnel incision was fashioned. A continuous curvilinear capsulorhexis was performed under a viscoelastic material (HPMC). The lens nucleus was mobilized using a balanced salt solution and a blunt hydrodissection cannula. Phacoemulsification was performed using the Oertli (Catarhex) phacoemulsifier with the phacochop and endocapsular techniques by an operating microscope, CarlZeiss-S7. A TECSOFT foldable acrylic IOL with a $6 \mathrm{~mm}$ phacoemulsification lens (Flex) was inserted under the viscoelastic material through a $3 \mathrm{~mm}$ opening. The viscoelastic material was aspirated.The wound was hydrated and an approximate physiological intraocular pressure was restored with a balanced salt solution injection through a side port. An intra-cameral injection of Cefuroxime $1 \mathrm{mg}$ was given at the conclusion of the surgery. A pad was then placed over the eye. The patient removed the pad when he/she reached at home and started post-operative prescription of Ofloxacin $0.3 \%$ eye drops four times daily and Prednisolone acetate 1\% eye drops six times daily was given to all the patients. All the patients' appointment was made for next day, one week and one month after surgery.

Data were entered and analyzed using SPSS version 19.0. Descriptive analysis was done with Chi-square test for significance testing. A p-value of $<0.05$ was considered statistically significant.

\section{RESULTS}

Nineteen (42.2\%) of them were men and 26 (57.8\%) were women. $69 \%$ of patients were above 60 years. All of them reported having experienced visual sensations during surgery, the most common being light perception $(100 \%)$, movements of instruments or surgeon's hands (91.1\%) and gush of water (62.2\%) (Table 1). One case (4.4\%) felt tolerable pain associated with fear $(P=0.000)$ due to these visual experience.

\section{Table 1: Questionnaire containing demographics and patients' visual experience}

\section{General patient details}

Name

Age

Sex

First/Second eye

Lens opacities grade

Anaesthetic details

Preoperative visual phenomena 


\begin{tabular}{lcc} 
Preoperative visual acuity & Better than $6 / 18$ & Less than $6 / 18$ \\
\hline Light perception & Yes & No \\
Movement & Yes & No \\
\hline Pain & Yes & No \\
Instruments & Yes & No \\
Gush of water & Yes & No \\
Finger & Yes & No \\
\hline Fear & Yes &
\end{tabular}

Table 2: Demographics and intraoperative visual experience associated with fear

\begin{tabular}{|c|c|c|}
\hline & Percentage finding visual experience (\%) & Level of significance with fear ( $p$-value) \\
\hline \multicolumn{3}{|l|}{ Age } \\
\hline$<60$ & 31.1 & 0.032 \\
\hline$>60$ & 68.9 & \\
\hline \multicolumn{3}{|l|}{ Sex } \\
\hline Male & 42.2 & 0.825 \\
\hline Female & 57.8 & \\
\hline \multicolumn{3}{|c|}{ Preoperative visual acuity } \\
\hline More than $6 / 18$ & 35.6 & 0.293 \\
\hline Less than $6 / 18$ & 64.4 & \\
\hline \multicolumn{3}{|c|}{ Light perception } \\
\hline Yes & 100 & \\
\hline No & 0 & \\
\hline \multicolumn{3}{|l|}{ Movement } \\
\hline Yes & 91.1 & 0.000 \\
\hline No & 8.9 & \\
\hline \multicolumn{3}{|l|}{ Pain } \\
\hline Yes & 4.4 & 0.000 \\
\hline No & 95.6 & \\
\hline \multicolumn{3}{|l|}{ Instruments } \\
\hline Yes & 37.8 & 0.270 \\
\hline No & 62.2 & \\
\hline \multicolumn{3}{|l|}{ Gush of water } \\
\hline Yes & 62.2 & 0.687 \\
\hline No & 37.8 & \\
\hline \multicolumn{3}{|l|}{ Finger } \\
\hline Yes & 40 & 0.066 \\
\hline No & 60 & \\
\hline \multicolumn{3}{|l|}{ Fear } \\
\hline Yes & 4.4 & \\
\hline No & 95.6 & \\
\hline
\end{tabular}




\section{DISCUSSION}

Topical anaesthesia shortens the duration of surgical time because it acts faster than the regional anaesthesia which takes a longer time to produce a desired effect. Also, the patients benefit from quickest visual recovery. Similar to previous literature, our study found that patients experience a wide range of visual sensations during cataract surgery under topical anaesthesia which included light perception, gush of water, movements and associated fear during surgery ${ }^{2-9}$.

In our study, all patients had light perception (100\%) and were able to fixate their eye with light of operating microscope during surgery. Similiarly, Chaudhary TA et al shows all of them reported having experienced visual sensations during surgery, the most common being light perception $(100 \%)^{10}$.

One case $(4.4 \%)$ reported having experienced fear $(p=0.000)$ due to the visual sensations. A study done by Haripriya A et al on effect of preoperative counselling on fear from visual sensations during phacoemulsification under topical anaesthesia shows a lower proportion of patients in the counselled group were frightened than in the group not counselled for light perception ${ }^{2}$. However, other study shows that the prevalence of frightening visual sensations (26.4\%) is higher than that reported in all previous published studies on this subject as all cases were operated under topical anaesthesia without preoperative counselling ${ }^{10}$. In a study done by Voon and colleagues reported a mean fear score of 0.3 in patients who received preoperative counselling compared to a mean fear score of 0.9 in those who did not ${ }^{11}$.

In this study, all patients received preoperative counselling about possible visual fear. The fear is a response to perceived threat which can be minimized by appropriate health education interventions ${ }^{12}$. It is well known that topical anaesthesia preserves optic nerve function ${ }^{13}$ and thus patients can experience a vast range of visual stimuli. So, preoperative counselling about possible visual fear could be of value for every patient scheduled to undergo phacoemulsification cataract surgery, in particular, regarding various possible stimuli such as light perception, gush of water and movements e.g. instruments, finger during surgery.

In this study, there was no statistically significant association between fear and visual perception like instruments, gush of water, finger,pre-operative visual acuity and sex. Similar study also concluded that there was no statistically significant association between fear and covariates such as age, gender, level of education, previous eye surgery and pre-operative visual acuity ${ }^{10}$.

Another study found that there were no associations between intraoperative visual impression and sex ${ }^{14}$.

Younger patients (<60 years) had visual experience more frightening than those over 60 years (P-0.032). Wickremasinghe SS et al found that although not statistically significant, younger subjects ( $<65$ years) tend to find the visual experience more frightening than those over 80 years (35.7 versus $21.4 \%)^{15}$.

\section{LIMITATION OF THE STUDY}

Though this study was non randomized and non controlled, preoperative counselling played role to minimize the intraoperative fear. But it needs further randomized and controlled study to strengthen the role of preoperative counselling.

\section{CONCLUSION}

Preoperative counselling about the potential intraoperative visual experience during phacoemulsification under topical anesthesia alleviates the visual experience fear in patients having cataract surgery.

\section{REFERENCES}

1. Hamilton RC, Gimbel H V, and Javitt JC. The prevention of complications of regional anesthesia for ophthalmology. Ophthalmol Clin North Am 3.1 (1990): 111-125.

2. Haripriya A, Tan CS, Venkatesh R, Aravind S, Dev A, Au Eong KG. Effect of preoperative counseling on fear from visual sensations during phacoemulsification under topical anesthesia. J Cataract Refract Surg. 2011;37(5):814-8.

3. Murdoch IE, Sze P. Visual experience during cataract surgery. Eye (Lond) 1994;8(Pt 6):666-667.

4. Rengaraj $V$, Radhakrishnan $M$, Au Eong KG, Saw SM, Srinivasan A, Mathew J, Ramasamy K, Prajna NV. Visual experience during phacoemulsification under topical versus retrobulbar anesthesia: results of a prospective, randomized, controlled trial. Am J Ophthalmol. 2004;138(5):782-787.

5. Au Eong $\mathrm{KG}$, Low $\mathrm{CH}$, Heng WJ, Aung $\mathrm{T}$, Lim TH, Ho SH, Yong VS. Subjective visual 
experience during phacoemulsification and intraocular lens implantation under topical anesthesia. Ophthalmology.2000;107(2):248-250.

6. Au Eong KG, Lim TH, Lee HM, Yong VS. Subjective visual experience during phacoemulsification and intraocular lens implantation using retrobulbar anesthesia. J Cataract Refract Surg. 2000;26(6):842846.

7. Au Eong KG. 6th Yahya Cohen Lecture: visual experience during cataract surgery. Ann Acad Med Singapore. 2002;31(5):666-674.

8. Tan CS, Au Eong KG, Kumar CM. Visual experiences during cataract surgery: what anaesthesia providers should know. Eur J Anaesthesiol. 2005;22(6):413419.

9. Prasad N, Kumar CM, Patil BB, Dowd TC. Subjective visual experience during phacoemulsification cataract surgery under sub-Tenon's block. Eye (Lond) 2003;17(3):407-409.

10. Chaudhry TA, Aqil A, Aziz K, Javed AA, Tauqir $M Z$, Ahmad K. Patients' visual experience during phacoemulsification cataract surgery and associated fear. BMC Res Notes. 2014 Sep 20;7:663.
11. Voon LW, Au Eong KG, Saw SM, Verma D, Laude A. Effect of preoperative counseling on patient fear from the visual experience during phacoemulsification under topical anesthesia: multicenter randomized clinical trial. J Cataract Refract Surg. 2005;31(10):1966-1969.

12. Grillon C. Models and mechanisms of anxiety: evidence from startle studies. Psychopharmacology.2008;199(3):421-437.

13. Tranos PG, Wickremasinghe SS, Sinclair N, Foster PJ, Asaria R, Harris ML, Little BC. Visual perception during phacoemulsification cataract surgery under topical and regional anaesthesia. ActaOphthalmol Scand. 2003;81(2):118-122.

14. Tranos PG, Wickremasinghe SS, Sinclair N, Foster PJ, Asaria R, Harris ML, Little BC. Visual perception during phacoemulsification cataract surgery under topical and regional anaesthesia. Acta Ophthalmol Scand. 2003 Apr;81(2):118-22.

15. Wickremasinghe SS, Tranos PG, Sinclair N, Andreou PS, Harris ML and Little BC. Visual perception during phacoemulsification cataract surgery under subtenonsanaesthesia. Eye (2003) 17, 501-505. 